\title{
Counting Cataloging: Moving Beyond Statistics to Measure the Value of Cataloging
} By Melissa De Fino and Jianrong Wang

\author{
Melissa De Fino \\ (Corresponding Author) \\ Special Collections Catalog Librarian \\ Technical \& Automated Services \\ Rutgers, the State University of New Jersey \\ 47 Davidson Road \\ Piscataway, N.J. 08854 \\ mdefino@rci.rutgers.edu \\ Voice: (732) 445-5903 \\ Fax: (732) 445-5888 \\ Jianrong Wang \\ Technical Services Librarian \\ The Richard Stockton College of New Jersey \\ P.O. Box 195 \\ Pomona, NJ 08240 \\ wangj@Stockton.edu \\ Voice: (609) 652-4571 \\ Fax: (609) 652-4964
}

\begin{abstract}
Given the budgetary and technological changes facing academic libraries, it has become necessary for librarians to become self-advocates, describing and defending the work they do. Most research in this area is dedicated to public services, with little focus on technical services. A survey conducted in the fall of 2009 found that catalogers in the sample state of New Jersey collect detailed productivity statistics to illustrate their value. This paper analyzes the statisticsgathering process and makes suggestions for developing these methods into a strong assessment model. Quality control assessment is the tool catalogers need to describe their worth to library stakeholders.
\end{abstract}

\section{Keywords}

- Cataloging

- Technical Services

- Cataloging Statistics

- Quality control assessment

- Productivity statistics 


\section{Introduction}

Two factors are driving rapid change in academic library landscapes: budgets are shrinking and the number of available information resources is growing. With more competition from outside sources and increasingly unstable funding, it has become more important than ever for librarians to illustrate the value of their work. They must outline exactly how libraries contribute to the overall missions of their institutions and why these services are important. Public services departments have the benefit of the user experience to provide evidence of their success. The user either has a positive experience or a negative one; they either find the information they required or they do not. The value of technical services, however, is not always as straight forward. How do catalogers demonstrate the importance of what they do to library stakeholders?

A survey was conducted in the fall of 2009 by the New Jersey Virtual Academic Library Environment (VALE) Bibliographic Control and Metadata Committee to better answer this question. The purpose of this survey was to discover how academic libraries in one sample state, New Jersey, are currently demonstrating their value by evaluating the quantity and quality of the cataloging and metadata services they provide. Having found that most technical services departments are gathering detailed statistics of their work, the study focused on the statistics gathering process itself. Do the statistics provide an accurate measurement of the value of the department? Activities examined included cataloging, database maintenance, and bibliographic quality control, the mainstay of cataloging and metadata work.

\section{Literature Review}

Little has been written on the statistics gathering practices of cataloging departments in academic libraries. Evaluations of individual cataloging functions have been conducted through the years but are not abundant compared with literature published on public services functions. The Minnesota Office of Library Development and Services, Continuing Library Education Network and Exchange published a book entitled Self-assessment Guide for Cataloging (Rehnberg, 1986). Although their book is aimed at public libraries and the scope is limited to cataloging skills, it demonstrates that in 1986, standards for catalogers had been established.

Elaine Sanchez (2007) administered a case study of nine cataloging agencies in academic libraries using the following categories identified as emerging issues in academic library cataloging and technical services:

- Description of university, library and staffing

- Cataloging productivity

- New technologies, enhancement of online catalogs

- Transition to metadata standards

- Cataloging of web sites and digital special collections

- Library catalog/metadata training and presentation

- Database maintenance, holdings, and physical processing 
- Relationship with acquisitions departments

- Staff education

- Other issues facing library cataloging staff

Sanchez concluded that in regard to cataloging productivity, "none of the libraries had specific cataloging quota," although some had task timelines for certain types of materials. All cataloging agencies placed quality control as a priority (Sanchez, 2007). Erin Czech and Israel Yañez applied the ten categories established in Sanchez's case study to the Cataloging Department at the University of San Francisco's Gleeson Library. Their findings coincided with Sanchez's in regards to cataloging quota. They also identified the same major changes and issues faced by cataloging departments (Czech \& Yanez, 2007).

In discussing performance indicators for technical services, Helen Hoffman identified that in cataloging and classification, "the throughput time, accuracy of service provided ... timeliness of supply and user failure rate at the catalogue or on the shelf can be measured. The unit cost of cataloging ... and the number of items cataloged per relevant member of staff can be tallied. ... Equivalent figures can be kept for the physical processing of materials." She continued that "once the data has been collected, a full statistical analysis is needed to make sense of the data and to be able to apply the results in a useful way." However, she observed that comparison of productivity among staff might raise questions, and quality of work is "very difficult to ascertain" (Hoffman, 1997). Patricia Dragon and Lisa Sheets Barricella described their "time-and-path" study experience, evaluating their workflow from the time materials were unpacked until they were shelf-ready for circulation (Dragon \& Barricella, 2006). They concluded that on average, it took longer for firm order materials to be processed than materials processed by PromptCat, now WorldCat Cataloging Partners (OCLC). After they analyzed the path that books traveled in technical services, they identified problems and streamlined their workflow, which improved efficiency.

There are ample studies on cataloging quality and quality standards. Marsha Starr Paiste conducted a literature review on cataloging quality. She argued that quality should be judged by the customer, not the producer. "Customer satisfaction is the goal" (Paiste, 2003). From the "Standards for College Libraries," (Association of College and Research Libraries, 2000), she detected "a recent trend in the evaluation of libraries has been the move away from numerical standards to assessment based on results" (Paiste, 2003). The problem is how a results-based evaluation can best be applied to cataloging work.

Ruth Fischer, Rick Lugg, and Kent C. Boese addressed this issue by establishing ten standard business principles that are relevant to cataloging activities:

1. Know current cost structures

2. Control the "Expert Mentality"

3. Adhere to standards

4. Maximize use of available resources

5. Design and produce an economically viable product

6. Adjust capacity to match demand 
7. Automate and/or outsource

8. Establish production goals and measure performance

9. Control quality via sampling

10. Be strategic

This business approach aims at saving time and lowering cost in cataloging operations. The authors offer concrete suggestions that can be applied to cataloging philosophy and practice, such as understanding cost, adhering to national standards, increasing record-acceptance criteria, decreasing review of non-essential fields and/or error correction, outsourcing wherever possible, establishing production goals, measuring performance, and finding practical ways of overcoming barriers (Fischer, Lugg, \& Boese, 2004).

\section{Methodology}

The survey was distributed via email to academic libraries throughout the sample state of New Jersey. Heads of cataloging and metadata services departments from fifty-three institutions in the state were contacted. Of those fifty-three, twenty-four institutions responded, resulting in a $45 \%$ participation rate. Most questions were multiple-choice with the option to select more than one answer, and included an additional optional open-ended section to encourage respondents to provide as much information as possible. Individual respondents and the institutions they represented remained anonymous. In order to study the possibility that library size plays a role in statistics gathering practices, the compiled data was filtered by library size and examined in three distinct categories:
a) Small $=0-99,999$ volumes
b) Medium $=100,000-499,999$ volumes
c) Large $=$ Over 500,000 volumes

\section{Results}

In terms of collection size, sixteen (70\%) institutions surveyed could be defined as medium in size, four (17\%) could be defined as small, and three (13\%) could be defined as large. An overwhelming majority of surveyed institutions (96\%) have less than ten staff members in their technical services departments. Only one (4\%) has between ten and twenty. The institution with the most staff compiles statistics monthly and collects statistics for seven types of materials, which is average. This suggests that departments with larger staffs do not necessarily gather more statistics than departments with smaller staffs. However, the two libraries with larger collection sizes do gather statistics on a wider variety of material types. One counts eleven formats or types of materials, including authority records; the other responded that it evaluates "everything." The size of a library's collection, then, apparently does have an impact on the type and extent of cataloging statistics that are gathered.

The survey included an open-ended question that asked for specific formats or types of materials catalogers are including in their statistics. Altogether, respondents listed thirty-four different formats and types of materials. Audio/visual and non-print materials, electronic resources, government documents, books, gifts, and serials were the most heavily recorded. Only 
one individual reported that they are not counting any specific resources separately from the rest of their workflow.

Most of the statistics collected represent new titles and volumes. Half of the surveyed institutions are also counting new copies. Few respondents are collecting data about recataloged material, indicating a significant gap in the appraisal of their work. Recataloging or modifying an existing bibliographic record requires a significant amount of time, but this information is not recorded as often as the number of records added to the system.

Regardless of what they are counting, all institutions are gathering statistical data on cataloging fairly regularly. The majority of respondents compile statistics monthly. Of these, two also compile additional yearly summaries. Three institutions only compile statistics yearly. Fewer than half of the surveyed institutions (37\%) are employing valuation mechanisms beyond statistics. For the majority of respondents, gathering statistics is the only means of illustrating the value of bibliographic control to their institution. The $37 \%$ that go beyond statistics look to user feedback, surveys, and interviews with users for evaluations of their work.

When asked about the cataloging functions they are recording, most departments reported that they are evaluating the productivity of their catalogers and the number of materials added to the collection. The majority of respondents stated that they are not recording how much time is spent cataloging a particular item. Less than $40 \%$ examine the quality of the completed bibliographic records. One respondent said their institution does not record statistics on cataloging at all.

Requesting specific examples from the respondents that do conduct quality control evaluations of bibliographic records revealed certain trends and commonly utilized methods. The quality control being conducted could be characterized as either informal or formal. Informal quality control consisted of randomly reviewing or target-checking bibliographic records. In institutions that conducted formal quality control, bibliographic records underwent a final review by a professional cataloger before they were released to the system. Problems were identified by scanning new book lists. Authority records were reviewed regularly. Respondents detailed methods of bibliographic record quality control that ranged from supervisors reviewing original records with or without the material in hand to scanning an output record of all field tags added to the system.

Respondents were asked what they considered to be the purpose of gathering statistics. Only two admitted that they were not sure. Most (75\%) reported that they assess cataloging functions because they believe it is good general management to do so. Justification of jobs, information for planning projects, and reports to outside agencies were also listed. One respondent noted that statistics are used "for planning purposes to make sure we have enough staff to handle resources and also for streamlining processes." Catalogers also compile statistics because they are required by outside agencies such as the Association of Research Libraries (ARL).

After statistics are collected, catalogers in $76 \%$ of surveyed institutions submit them to their department heads for analysis. Seventy-one percent said the cataloging staff and faculty are

Pg. 5 
also responsible for analyzing results. Among $29 \%$ of surveyed institutions, this responsibility falls to library administration. A large majority of institutions are compiling statistics within the department rather than involving library administration or an outside source. However, one institution reported that their statistics were even analyzed by their university-level administration.

In addition to examining what statistical data catalogers are counting, the survey was formulated to discover how they are compiling statistical data. Traditionally, statistics in cataloging and metadata services departments are collected by hand. It was found that while catalogers are now able to use their ILS to compile and analyze statistics, half of them are also still recording their statistics by hand. In many cases, this is because the ILS is not able to produce the statistical results that are required. Despite all the changes and technological advancements made in library assessment, statistics gathering practices in the surveyed institutions have not seen much progression.

\section{Discussion}

\section{The problem}

Best practices dictate that assessment should be based on concrete results, on the impact to the user experience and contribution to the institution's overall mission. However, the findings suggest that in New Jersey academic libraries, cataloging and metadata departments are gathering statistics on productivity and collection size to measure their value. They count by format and type of material, by volume and by copy number, and by how much the collection grows with every new item cataloged. The types of statistics gathered and the method of statistics gathering has not changed along with the rest of the profession. The information is recorded because it is required, either by department heads or library administrations, or by outside agencies such as ARL. It is used by administrators to maintain staffing levels and plan for future projects, but does not adequately measure the value of cataloging and metadata departments. Collecting statistics may satisfy productivity queries, but it does not show the impact of cataloging work to users.

\section{The solution}

Further study is required on the impact of cataloging productivity and bibliographic quality control on teaching and learning in the academic environment. New models and methods need to be established. Productivity statistics need to be linked to users to demonstrate value. The impact of cataloging on users and the overall institution is not only evidenced by the amount of bibliographic records being created, but by the quality of those records. Within the surveyed institutions that are including quality control among their statistical evaluations there can be found some potential best practices for quality control evaluation. Institutions are conducting either informal or formal quality control. Informal quality control is performed on an as-needed basis. Errors are corrected as they are reported. Administrators periodically request quality analyses to be run on the system. Formal quality control is conducted more regularly. Every bibliographic record is reviewed. Bibliographic and authority reports are run regularly and 
monitored for errors by database managers or administrators. Records created by paraprofessionals or new catalogers are approved before they are released.

Given the current budgetary limitations of libraries, it is of course not realistic for every bibliographic record to be reviewed for quality. Formal and informal quality control methods must be used simultaneously. Technology available in the ILS could be better utilized for global evaluations and improvements of the online catalog. This is something that many cataloging departments are already doing, but that information is not reflected in their statistics. Rather than showing library stakeholders how they have helped the collection grow, catalogers should show how they have helped the collection develop. Most respondents to the survey are not reporting recataloging in their statistics at all.

Many of the surveyed institutions that are examining quality control in their catalogs are also using methods of review beyond statistics. They reported utilizing user feedback, surveys, and interviews with users for evaluation. Improving communication between technical services and the user has two benefits. Users and library stakeholders are made aware of the value of technical services to the libraries and the overall institution and cataloging and metadata librarians are made aware of the ways in which they can improve the user experience.

Other suggested approaches to evaluating quality control in cataloging and accessibility include usability testing, log analysis, and focus groups. Cataloging departments might also consider the Balanced Scorecard (BSC) business model as a method to measure the department's overall performance. This model has been used by the University of Virginia Libraries to measure their turnaround time for patron-requested materials. It could be expanded to assess cataloging productivity with reachable goals and target timelines (University of Virginia Library). The University of Kansas model could also be adopted and extended. The University of Kansas designed their own instrument to determine the library staff's perception of the services provided by the cataloging department. Disappointed by SERVQUAL's missing surveys in technical services, they decided to use four out of ten SERVQUAL dimensions which were considered relevant to measure their library staff's perception of the department's service: reliability, responsiveness, assurance, and empathy. The results found that the majority services were rated 6 to 8 on a scale of 1 to 9 , and the staff believed that the department was most successful in providing consistency within the ILS by maintaining authority control, solving problems, and correcting errors. Cataloging staff also recognized room for improvement in providing bibliographic access to electronic resources (Gibbs, 2002).

\section{Conclusion}

Considering the various changes and challenges facing libraries today, the very survival of the cataloging profession is dependent on how catalogers describe their work to library stakeholders. Traditional methods of measurement are no longer sufficient. It cannot be assumed that Cataloging will continue to be a line on academic library budgets simply because it has always been so. Catalogers must become self-advocates.

Beyond productivity, quality control statistics need to be recorded and analyzed to exhibit how they improve the academic experience of the user, because the user experience is the most 
important component of library evaluation. As Steve Hiller and Jim Self stated in their 2008 library assessment program, "common library measures/statistics ...don't tell us the value to the users..." Cataloging services and activities need to be "viewed through the eyes of customers" (Hiller \& Self, 2008). Productivity is important, but does not distinguish libraries from other information sources. Other resources can bring users large search results. It is in libraries that users should expect to receive reliable and accurate results that improve their research. This is the value of cataloging work.

New methods of measurement need to be explored to tell the cataloger's "story," a story that "focuses on customer information needs and services" and "customer outcomes" (Hiller \& Self, 2008). These methods of measurement should move Cataloging from the traditional statistics-gathering model to a true model of assessment, where data is focused not on productivity but on impact to the user. To echo Steve Hiller and Jim Self, library assessment is "not about us! It's about the customer!" (Hiller \& Self, 2008)

\section{Acknowledgement}

The authors wish to thank the VALE Bibliographic Control and Metadata Committee Research Subcommittee, and especially the subcommittee's chair Kathleen Hughes, for their assistance, guidance, and support.

\section{References}

Association of College and Research Libraries. (2000). Retrieved September 30, 2010, from Standards for College Libraries: http://www.tamuk.edu/sacs/newsacs/pdfs/Mastdoc/other/ACRL.pdf

Czech, E., \& Yanez, I. (2007). Evaluation of the Cataloging Department at the University of San Francisco's Gleeson Library. Retrieved December 7, 2009, from http://israelsjsu.net/eportfolio/GleesonEvaluation.pdf

Dragon, P., \& Barricella, L. S. (2006). Assessment of Technical Services Workflow in an Academic Library: a Time-and-Path Study. Technical Services Quarterly, 1-16.

Fischer, R., Lugg, R., \& Boese, K. C. (2004). Cataloging: How to Take a Business Approach. The Bottom Line: Managing Library Finances , 50-54.

Gibbs, G. E. (2002). Service Quality in Cataloging: the Experience of the University of Kansas Libraries. In J. Stein, M. Kyrillidou, \& D. Davis (Eds.), Meaningful Measures for Emerging Realities: Proceedings of the 4th Northumbria International Conference on Performance Measurement in Libraries and Information Services (pp. 215-222). Washington, D.C.: Association of Research Libraries.

Hiller, S., \& Self, J. (2008). Library Assessment: Measuring and Documenting the Library's Contribution to Academic Success. Network Summer Faculty Enrichment Program. New York, N.Y.: New York University. 
Hoffman, H. (1997). Performance Indicators for Technical Services in Academic Libraries. Australian Academic and Research Libraries , 259-263.

OCLC. (n.d.). Retrieved March 8, 2010, from PromptCat: http://www.oclc.org/us/en/promptcat/

Paiste, M. S. (2003). Defining and Achieving Quality in Cataloging in Academic Libraries: a Literature Review. Library Collections, Acquisitions, \& Technical Services , 327-338.

Rehnberg, M. (1986). Self-assessment Guide for Cataloging. St. Paul, Minnesota: Minnesota Office of Library Development and Services, Continuing Library Education Network and Exchange.

Sanchez, E. (2007). Emerging Issues in Academic Library Cataloging \& Technical Services. [U.S.]: Primary Research Group, Inc.

University of Virginia Library. (n.d.). Retrieved June 15, 2010, from Balanced Scorecard: http://www2.lib.virginia.edu/bsc/index.html 